MATEC Web of Conferences 23,0 01056 (2015)

DOI: $10.1051 /$ matecconf/ 20152301056

(C) Owned by the authors, published by EDP Sciences, 2015

\title{
Experimental research conception of thin liquid film boiling and evaporation
}

\author{
Dmitry V. Feoktistov, Evgeniya G. Orlova and Victor D. Velicanov \\ Thermal Theory and Engineering Department, National Research Tomsk Polytechnic University, \\ 634050, Tomsk, Russia
}

\begin{abstract}
The concept of conducting the experiments for studying thin liquid film boiling and evaporation was developed. Implementing this conception on developed experimental setup, we will obtain the data on the change of liquid film thickness in thermosiphon and temperature distribution in the liquid film, also the evaporation rate of liquid film and heat transfer coefficient change will be calculated using the measured values in the experiment. Three series of preliminary experiment were conducted. As a result, the main influencing factors and their values were defined.
\end{abstract}

\section{Introduction}

Nowadays, the development of aviation industry in all major corporations (US, EU, Russia) is on the path of increase in quantity of energy-filled equipment. At the same time, the most significant problem of the developers at aviation equipment designing is thermal control system of aircraft equipment (radio electronics, operating control, air conditioning systems, etc.). The relevance of this scientific-technical problem is proved by accident situation arising owing to fires of storage batteries installed on new aircraft. Recently, there is a slowdown of cooling system development in the aerospace industry (in particular, in thermosiphon units). It is caused by a small number of publications devoting to experimental researches of thin liquid film boiling and evaporation. Having regard to the above, it is proposed to develop the concept of experimental studies of thin liquid film phase transitions $[1,2]$.

The aim of this work is to develop the concept of conducting the experiments for studying thin liquid film boiling and evaporation. In particular, data on the change of liquid film thickness in thermosiphon and temperature distribution in the liquid film will be obtained from direct measurements. Dependences on evaporation rate of liquid film and heat transfer coefficient change will be calculated using the measured values in the experiment.

\section{A scheme of the experimental setup and experimental method description}

For conducting the researches of thin liquid film boiling and evaporation in thermosiphon, the experimental setup was developed. A scheme of setup is presented in Figure 1. 


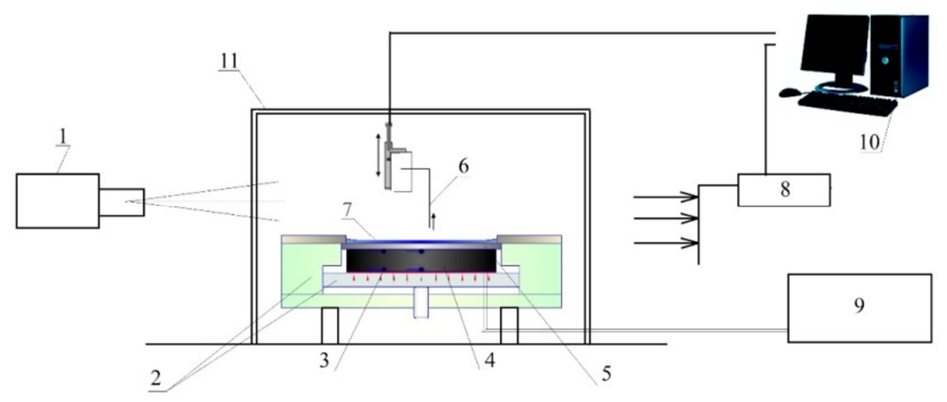

Figure 1. A scheme of experimental setup: 1 - photo camera; 2 - heat-insulating wall; 3 - thermocouples; 4 metal plate; 5 - substrate; 6 - feeler gage; 7 - liquid; 8 - analog-digital converter; 9 - power source; 10 computer; 11 -glass box.

At the beginning of the experiment a horizontal liquid layer 7 is formed in a test cell by a syringe pump (with accuracy of 5\%). Layer thickness varies depending on the experimental operating parameters (substrate and liquid initial temperatures) and must to be not more than $5 \mathrm{~mm}$. The minimum layer thickness depends on the sample liquid viscosity. It is about $1.5 \mathrm{~mm}$ for ethyl alcohol. There is a destruction of a layer with decreasing its thickness. A liquid layer opens to the atmosphere, and it can greatly simplify the optical measurements and visualization of processes using the camera 1 (CANON D7100). A liquid layer is heated from the side of the substrate 5 by means of the flat heating element MINCO $275 \mathrm{ohms}$, installed in the test cell. This heating element consists of piezoelectric cell. Power is controlled by the power source (9 GPD-73303D). The temperature of the heating element, liquid and ambient gas is measured using six chromel-alumel thermocouples 3 (OMEGA 304 SS Sheath). Data collection is done by control-measuring system, consisting of the analog-digital converter ADC 8 (NI cDAQ-9171) and LABVIEW Signal Express software. Temperature measurement accuracy is $0.1^{\circ} \mathrm{C}$.

To measure and control the liquid thickness, feeler gage (needle) made of stainless steel and precision miniature linear actuator Zaber T-LA-28A are used. The slope of the test cell to the horizontal is determined using a goniometer (THORLABS GN05/M) in two planes. The setup is installed on an optical plate (THORLABS 1B-AL-30-60-015-BL), which provides the necessary accuracy in adjustment of the optical equipment and makes it easy to modify the setup and place the additional devices. The flatness of plate is $\pm 0.25 \mathrm{~mm}$.

Figure 2 presents the test cell concept. The test cell consists of the substrate 5 , the metal plate 1 , the heating element 2 and the case 4 made of insulating material. It is assumed that the substrate 5, the metal plate 1 and the heating element 2 are in direct contact with each other. The insulating wall 4 is designed to minimize heat loss to the environment. The test cell is a round opening with a diameter of $50 \mathrm{~mm}$, limited by case wall with $5 \mathrm{~mm}$ in height, and the substrate. The metal plate 1 with the heating element 2 (MINCO $275 \mathrm{ohms}$ ) is placed under the substrate 5 to transfer heat through the substrate layer directly to liquid 6 . The test cell is surrounded by heat-insulating wall 4 with the bottom and side. The flat heating element 2 , the metal plate 1 and the substrate 5 are installed alternately in the cutout the case. The metal plate has four holes for thermocouples, namely the upper and lower surfaces in its central part and at a distance of half of radius from the center of the case cutout.

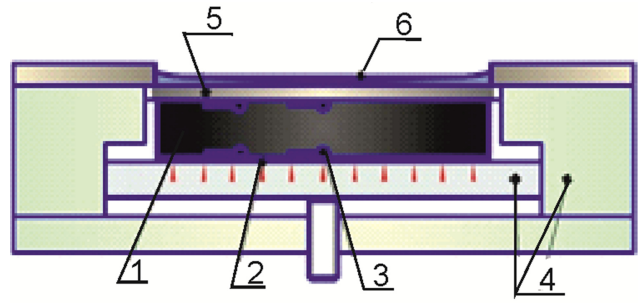

Figure 2. Concept of the test cell: 1 - metal plate; 2 - heating element; 3 -thermocouples; 4 - heat-insulating wall; 5 - substrate; 6 - liquid layer. 
We use a thin needle (diameter of 300 microns across the length and $50 \mathrm{~mm}$ at the tip) as the feeler. Its position is determined by the precision miniature linear actuator T-LA-28A. Minimum movement step of the actuator is 0.09 microns; the accuracy of position is 24 microns. The range of actuator movement is $50 \mathrm{~mm}$. The precision actuator is connected to a personal computer and is controlled by special software Zaber Console. Observation over the feeler and image recording are carried out using photo camera with a resolution of $1280 \times 1800$ pixels.

Method of liquid layer thickness measuring consists of two stages (Figure 3). The first stage is characterized by measuring the distance $\mathrm{H}_{0}$ from the initial position of the feeler 1 to the substrate surface. In the second stage, after formation of the liquid layer 2, the distance from the initial position of the feeler to the liquid surface $1 \mathrm{H}_{\mathrm{s}}$ is measured. The liquid layer thickness is determined by the difference of these distances $\mathrm{H}_{1}\left(\mathrm{H}_{1}=\mathrm{H}_{0}-\mathrm{H}_{\mathrm{s}}\right)$.

The metal plate (heating element), which is placed in direct contact with the substrate, is energized. At achieving the required temperature the liquid is placed on the substrate. Afterwards, the liquid layer initial thickness is measured using the feeler and actuator. After measuring the thickness, collecting the data on temperature of the heating element, liquid and environment starts. Their signals are recorded via thermocouples mounted in different parts of the heating element. Then signals are received to the converter, and data is displayed using the Signal Express software. The liquid layer thickness is measured several times in certain intervals until complete evaporation.

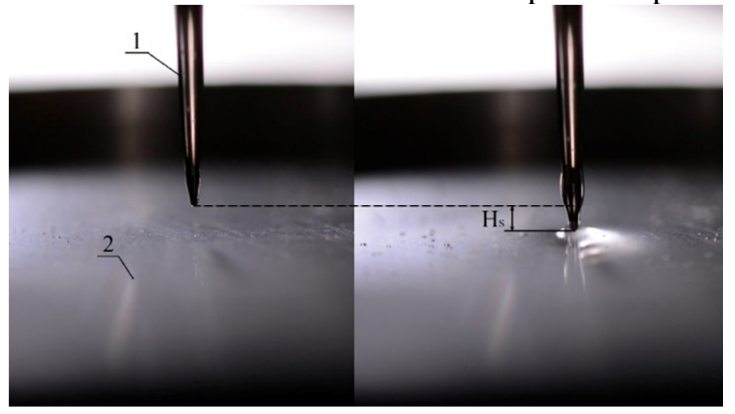

Figure 3. Method of liquid layer thickness measuring: 1 - feeler; 2 - liquid layer.

According to the results of preliminary experiments, the values of influencing factors were determined (Table 1). Varying the voltage of the source is limited by the maximum possible capacity of the device and, on the other hand, the necessity to provide an extremely high evaporation rate of the liquid layer. Varying the liquid layer thickness is limited by a minimum thickness to provide the layer integrity at a given temperature, and on the other hand, the maximum height of the wall in test area (5 $\mathrm{mm})$.

The choice of material and the surface roughness is limited by available substrates. However these parameters can influence significantly on liquid boiling and evaporation [3-5].

Table 1. Influencing factors

\begin{tabular}{|c|c|c|}
\hline Factor & Factor value \\
\hline Liquid layer thickness, $\mathrm{mm}$ & \multicolumn{2}{|c|}{$1-5$} \\
\hline Substrate temperature, ${ }^{\circ} \mathrm{C}$ & \multicolumn{2}{|c|}{$65-120$, with increment of $5^{\circ} \mathrm{C}$} \\
\hline Substrate material & $\begin{array}{c}\text { Stainless-steel, } \\
\text { Plexiglas with gold sputtering, }\end{array}$ \\
\hline
\end{tabular}

The output parameters are mass evaporation rate, heat transfer coefficient from the liquid surface, temperature distribution in the liquid layer. As a working liquid we suppose to use volatile liquids (ethyl alcohol). 


\section{Experimental results}

To complete the experimental research concept, preliminary investigations were conducted. Experimental results are presented in Figure 4.

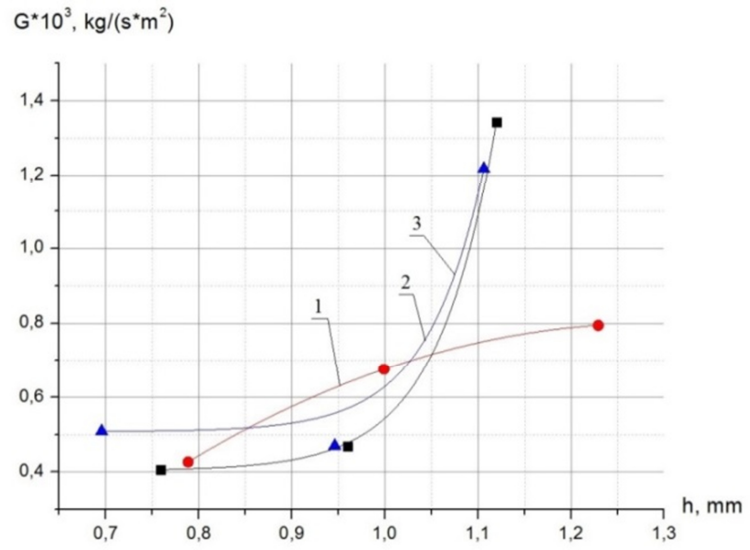

Figure 4. Mass evaporation rate versus liquid layer thickness: 1 -first experimental series; 2 -second experimental series; 3 - third experimental series.

Ambient temperature during the experiment was $26^{\circ} \mathrm{C}$, temperature of the plate at the initial time was $55^{\circ} \mathrm{C}$.

Three experimental series were conducted with the same initial temperature of the substrate and liquid layer thickness at the initial time. Measuring the liquid layer thickness was held with the following time intervals:

1 -layer thickness measurement at the initial period of time;

$2-130$ seconds after beginning the experiment;

$3-270$ seconds after beginning the experiment;

$4-390$ seconds after beginning the experiment.

During conducting the experiments with the test cell open to the atmosphere, ambient conditions is found to have significant impact on the measurements.

The substrate temperature is found to decrease during liquid evaporation, if low boiling liquid (alcohol) is used. Decreasing the temperature can be avoided or significantly reduced by isolating the test cell from the atmosphere. For this purpose, the glass box (4 mm thick) was designed. The openings in the box are provided to access to the feeler and actuator. Also the opening is provided for photographing the moment of the needle and liquid layer contact. This box will also reduce the impact of environmental factors on the evaporation.

It is worth noting, that during the evaporation process at a certain thickness of ethyl alcohol (about 1 $\mathrm{mm}$ ), and the surface tension forces ensure discontinuities in the liquid layer in areas heat supply to the substrate. In these areas, thermocouples recorded rise in temperature, while in the areas where the liquid layer has been formed, the temperature decreased.

The work was held within the research state assignment "Science" №13.1339.2014/K (Code of Federal Target Scientific and Technical Program 2.1410.2014).

\section{References}

1. V.S. Ajaev, E.Ya. Gatapova, O.A. Kabov, Microgravity Sci. Technol. 24, 33 (2012)

2. E.G. Orlova, I. A. Afanasyev, D. V. Feoktistov, EPJ Web of Conferences 82, 01054 (2015)

3. S.Y. Misyura, V.E. Nakoryakov, S.L. Elistratov, Int. J. Heat Mass Transfer 55, 6609 (2012)

4. E.G. Orlova, G. V. Kuznetsov, MATEC Web of Conferences 19, 01006 (2014)

5. V. E. Nakoryakov, S. Ya. Misyura, Doklady Physics 59, 441 (2014) 